\title{
Missile Defense and NATO Security
}

\author{
Peppino A. DeBiaso *
}

For our readers who noted the article on missile defense policy in the Fall 2008 edition, which provided a Russian point of view, this article, reprinted from the Joint Force Quarterly, provides a U.S. point of view on the subject.

Henri Bigo, Executive Director, PfP Consortium

Armed with weapons of mass destruction (WMD), the global proliferation of ballistic missiles is introducing more widely the means of modern strategic warfare that were once the purview of only a small number of countries. This transformation in the security environment raises new questions for the North Atlantic Treaty Organization (NATO) on the strategic implications of defending its territory against ballistic missile attack. During the recent NATO summit in Bucharest, Romania, the Alliance acknowledged for the first time that missile defense can make a contribution to protecting NATO territory and populations from attack. Consequently, NATO is undertaking an intensive examination of the issues associated with a comprehensive continental defense against ballistic missiles to enable it to counter future military risks.

\section{Emerging Security Environment}

The threats to the security of the United States and its NATO allies have changed significantly since the early 1990s and the demise of the Soviet Union. A broader and more complex range of challenges confronts the Alliance today. Prominent among these are the proliferation of destructive technologies, such as nuclear, biological, and chemical weapons and the ballistic missiles to deliver them at great distances. Ballistic missiles capable of carrying WMD have become the weapon of choice for an increasing number of states that view them as low-cost, high-impact arms capable of offsetting Western military advantages. And the danger they pose is expanding in Northeast and South Asia, as well as the Middle East.

In the 1970s, at the height of the Cold War, nine nations possessed ballistic missiles. Today, more than twenty states have these weapons. Furthermore, these missiles are undergoing improvements in range, accuracy, mobility, and ability to carry a variety of conventional and unconventional warheads. Over the past decade, in addition to the roughly two-dozen states operating short-range ballistic missiles (up to 1,000 kilometers), the number of countries with medium-range $(1,000-2,500 \mathrm{~km})$, intermediaterange $(2,500-5,500 \mathrm{~km})$, or intercontinental-range (greater than $5,500 \mathrm{~km}$ ) ballistic missiles has increased from five to nine. Not only has the number of nations possessing

\footnotetext{
Dr. Peppino A. DeBiaso is Director of the Office of Missile Defense Policy in the U.S. Department of Defense. This article was originally published in Joint Forces Quarterly 51 (4 ${ }^{\text {th }}$ Quarter 2008).
} 
ballistic missiles been growing, but this group also includes some of the most dangerous regimes in the world, such as North Korea and Iran.

North Korea has an ambitious ballistic missile development program and is a major exporter of missiles and missile technology to other countries, including Iran, Syria, and Pakistan. North Korea has long possessed a large arsenal of short-range ballistic missiles (SRBMs) and medium-range ballistic missiles (Mobs). Through the 1990s, it was also able to develop or acquire the technologies for ballistic missiles capable of striking other continents. In August 1998, it tested the three-stage Taepo Dong 1 missile in an attempt to orbit a satellite. The missile's third stage failed, but not before it flew long enough to prove that North Korea had the basic technologies necessary for longer-range ballistic missiles. Pyongyang is now developing several such longer-range weapons, including a new intermediate-range ballistic missile (IRBM) with a range estimated at 2,500 km. In July 2006, North Korea conducted seven widely publicized launches. It successfully fired six theater-class SRBMs and Mobs, demonstrating the capability to conduct salvo strikes against U.S. forces in the region, as well as South Korea and Japan. The seventh missile, the Taepo Dong 2 space launch vehicle/ intercontinental ballistic missile, was flown for the first time. The Taepo Dong 2, capable of carrying a nuclear payload, could reach much of the Asia-Pacific region and parts of the United States when operational. Although the Taepo Dong 2 failed shortly after launch, the test made clear the significant program North Korea has under way to build ever more sophisticated missiles with global reach.

In the Middle East, while several states are fielding new and improved SRBMs and Mobs, Iran represents the most serious concern because it unites a vigorous ballistic missile program, the development of key capabilities needed to produce nuclear weapons, the demonstrated use of missile-delivered chemical weapons (against Iraq in the 1980s), and the stated desire to destroy nearby countries (namely Israel). Iran also has a history of support for international terrorism, especially in terms of weapons transfers. Most recently, Iran reportedly supplied the Lebanese Shiite militia Hezbollah with both long-range rockets and short-range ballistic missiles, with the former used against civilian population centers in Israel during the conflict in 2006. Iran already has the largest inventory of SRBMs and Mobs in the region to underpin its growing freedom of action throughout the wider Middle East.

Iran's plans to deploy longer-range ballistic missiles go beyond the capacity needed to strike U.S. forces and allies in the Middle East. It is developing technology for missiles of increasing range and sophistication, which will allow it to threaten Europe. Iran is modifying its 1,300-km Shahab-3 MRBM in order to give it greater range. In 2004, it claimed that it had successfully extended this missile's range to $2,000 \mathrm{~km}$. If true, Iran can now target large portions of the Near East and Southeastern Europe, along with U.S. and NATO bases and deployed forces in Turkey and Central Asia. Tehran recently announced that a new solid propellant MRBM - the Ashoura - is in development and could begin flight testing soon. It also continues to work closely with North Korea on ballistic missiles of longer range. As a result of ongoing foreign assistance, Iran's Mobs and IRBMs could develop more rapidly than would be possible on the basis of its indigenous capabilities. According to multiple open source reports, Tehran 


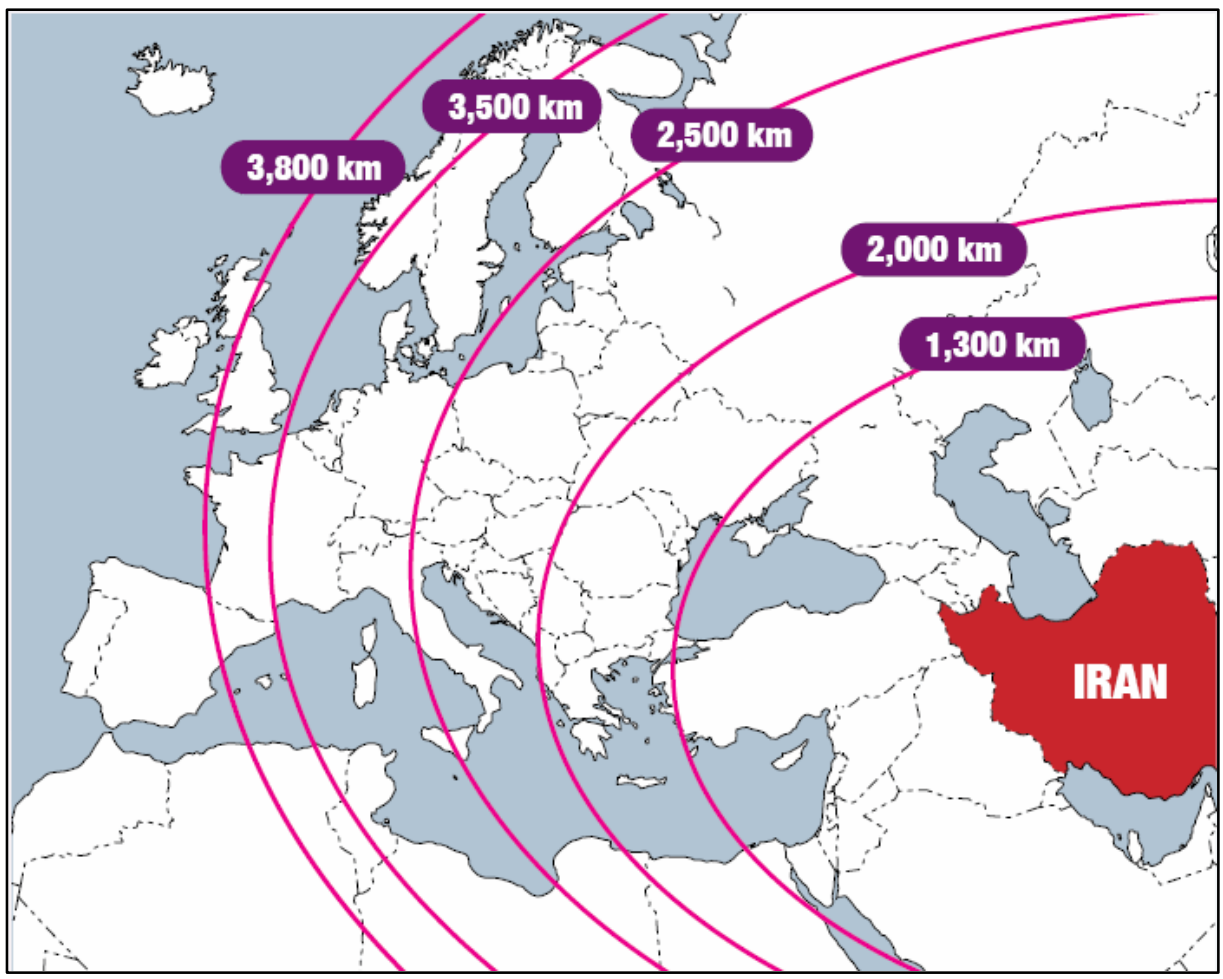

Figure 1: Current and Projected Ranges of Iran's Missiles.

has acquired from North Korea 2,500-km-range missile systems. As with most ballistic missiles, the possibility to extend this range exists through improving the design of the airframe or using lighter payloads. A range increase to 3,500-3,800 km would allow Iran to reach European targets as far west as the United Kingdom (as shown below in Figure 1). Additionally, it continues to develop the key technologies for an intercontinental-range ballistic missile and a space launch vehicle, giving it multiple paths to achieving weapons capable of striking the United States by the middle of the next decade.

The spread of ballistic missiles and missile technology has been accompanied by corresponding trends in the area of WMD. This is the case for two major reasons. First, there are more than twenty nations today that possess or are seeking to acquire nuclear, biological, or chemical capabilities that can be carried by ballistic missiles. Second, in the past decade, the proliferation of WMD technologies and the expertise required to "weaponize" them have been accelerated by the willingness of both state and non-state organizations to collaborate to advance these programs. This became evident with the revelation in 2003 that A.Q. Khan, known as the "father" of Pakistan's nuclear 


\begin{tabular}{|c|c|c|c|}
\hline Country & Type & Dates & Purpose \\
\hline Iraq against Iranian cities & Scuds & $1980-1988$ & Political: Incite fear in civilian population \\
\hline Iran against Iraqi cities & Scuds & $1985-1988$ & Political: Incite fear in civilian population \\
\hline Libya against U.S. naval facilities in Italy & Scuds & 1986 & Military: Response to U.S. airstrikes on Libya \\
\hline $\begin{array}{l}\text { Soviet Union against mujahideen forces in } \\
\text { Afghanistan }\end{array}$ & Scuds & $1988-1991$ & Military: Destroy rebel forces in Afghanistan \\
\hline Iraq against Israel, Kuwait, and Saudi Arabia & Scuds & 1991 & Political: Attempt to split coalition \\
\hline Iran against Iranian dissident camps in Iraq & Scuds & 1994 & Military: Destroy Iranian dissidents \\
\hline $\begin{array}{l}\text { South Yemen against North Yemen during } \\
\text { civil war }\end{array}$ & Scuds & 1994 & $\begin{array}{l}\text { Military: Destroy rebel forces in North } \\
\text { Yemen }\end{array}$ \\
\hline China launches near Taiwan & CSS-6s & 1995-1996 & $\begin{array}{l}\text { Political: Attempt to influence elections on } \\
\text { Taiwan }\end{array}$ \\
\hline Russia against targets in Chechnya & SRBMs & 1999-2000 & Military: Destroy rebel forces in Chechnya \\
\hline Iraq against U.S.-led coalition forces & SRBMs & 2003 & Military: Destroy coalition forces \\
\hline
\end{tabular}

Figure 2: Ballistic Missile Use since 1980.

weapons program, had built an international network of suppliers and expertise over several decades to sell nuclear bomb-making design information and technology to several countries, including Iran, Libya, North Korea, and Syria.

The consequences of these activities are beginning to emerge. In October 2006, North Korea carried out a nuclear weapons test. Its progress in developing a nuclear device (along with any foreign assistance it may have received) went largely undetected. Moreover, North Korea continues to provide assistance to other states' nuclear programs, as suggested by recent events regarding its cooperation with Syria on a nuclear reactor. The disclosure in 2007 that Iran had a covert nuclear weapons program for many years further highlights the difficulty of accurately predicting the emergence of new nuclear weapons states. A 2007 U.S. National Intelligence Estimate (NIE) concludes that, although Iran appears to have suspended some aspects of this program, it is keeping its options open on nuclear weapons. Indeed, Iran's ongoing pursuit of enriched uranium is the crucial element it its capacity to bring a nuclear capability to fruition. Its activities in this area, combined with its program to build longer-range missiles, reflect its commitment to acquiring strategic arms.

All of these troubling indicators are characteristic of today's security environment. The spread of WMD technologies along with missile delivery vehicles is increasing the strategic warfare potential of regional powers and will influence the shape of future crises and conflicts. Indeed, states have already demonstrated a willingness to use ballistic missiles to serve a variety of political and military goals. As illustrated in Figure 2, there have been at least ten conflicts since the early 1980s in which states have conducted missile launches against civilian as well as military targets. This also has included the employment of ballistic missiles armed with WMD that occurred when Iraq and Iran used chemical weapons in the 1980-88 "War of the Cities," killing and injuring tens of thousands. 


\section{Responding to New Threats}

The United States and its allies are considering how best to counter these new threats - namely, the prospect of catastrophic weapons falling into the hands of a rising number of countries with the ability to deliver them trans-regionally and with little warning. The United States, for its part, has taken steps to field missile defenses against these arms in order to underwrite four key global security goals.

First, missile defense can serve as a valuable instrument - along with diplomatic and political measures - to combat WMD proliferation and support nonproliferation efforts. Defenses may dissuade adversaries from choosing to acquire or expand ballistic missile arsenals by negating any advantage that they might hope to achieve by building them in the first place. In the presence of defenses, ballistic missiles launched by hostile states would no longer have a "free ride" against the population centers or deployed forces of the United States and its allies. Defenses would make ballistic missiles an unwise military investment with diminishing utility. Missile defense can further strengthen the goal of nonproliferation by providing allies the means to protect themselves against a nuclear-armed adversary without having to acquire their own nuclear deterrent. This is the path Japan has taken, developing a layered missile defense system in cooperation with the United States to protect its population centers and military forces against the threat of a North Korean missile attack.

Second, missile defense provides the leadership of the United States and its allies with a wider range of responses to manage crises and conflicts beyond the immediate use of offensive weapons. This was demonstrated during the North Korean launch preparations of the Taepo Dong 2, when the United States placed its missile defense system on operational alert for the first time. Although still limited in its capabilities, the system was prepared to defend the United States against any North Korean longrange ballistic missile. While some national security experts called for preemptive strikes against the North Korean missile and its launch facility, missile defenses gave American decision makers an option beyond preemptive strikes that, in turn, contributed to stability during the crisis.

Third, by diminishing the likelihood of a successful attack, missile defense can enhance traditional offense-based deterrence by introducing doubt and uncertainty into a potential adversary's plans to attack. By denying the achievement of the political or military goals of any contemplated threat or actual strike, defenses would reinforce the deterrence of aggression. Finally, and most importantly, missile defense provides protection to threatened population centers and deployed forces against actual attack should deterrence and diplomacy not succeed in preventing a conflict.

The missile defense approach the United States is taking to address threats to its national territory as well as to its forces abroad involves a number of elements. To protect its troops and those of its coalition partners against shorter-range missiles, the Pentagon is fielding ground- and sea-based interceptors and tracking radars along with sensors on land, at sea, and in space. These include the land-based Patriot Advanced Capability-3 (PAC-3) and the Terminal High Altitude Area Defense systems for defense against short- and medium-range ballistic missiles for forward operating troops, 
military bases, and combat staging areas. Also being deployed are sea-based missile defense systems on Aegis-class ships, which will provide a mobile capability against missile attack. These are being fitted to carry the Standard Missile-3 (SM-3) interceptors to counter short- and medium-range ballistic missiles.

To defeat longer-range ballistic missiles, the United States is establishing a groundbased defense system in Alaska and California. The Ground-Based Interceptor (GBI) will engage intermediate- and long-range ballistic missiles in the midcourse phase of flight, hundreds of kilometers above the Earth. This ground-based defense-which is supported by space-based sensors and land- and sea-based radars-will allow the United States to defend itself against missiles launched from Northeast Asia or the Middle East. The U.S. missile defense system, with approximately fifty Gibes planned for deployment by 2013, is designed to provide a modest defense against a few tens of long-range ballistic missiles.

As ballistic missile and WMD threats change over time, so will the composition of missile defense forces. Adjustments to the number and locations of defenses will be based on new or emerging dangers. Some threats (like Libya) may recede, while others (like Iran) may grow. Given the uncertainty in forecasting the timing and location of adversaries possessing such weapons, and the many years required to build and field defenses, the United States and its allies must consider how to have systems in place before a threat fully emerges.

\section{Missile Defenses in Europe}

Against the backdrop of the global proliferation of ballistic missiles and WMD technologies, the United States is advancing a range of initiatives to extend the benefits of missile defense to its allies. As NATO territory comes under increased risk of ballistic missile attack, the ability of the Alliance to preserve its freedom to act across the full spectrum of military conflict - from humanitarian and peace enforcement interventions to conventional operations-will require some measure of Alliance protection. Over time, defenses that only protect the United States may lead to the decoupling of U.S. security from that of its allies. This would undermine the indivisibility of Alliance security, which has been the bedrock of NATO since its founding. However, by extending the protection afforded by missile defenses to Europe, it is possible to offer a set of capabilities to blunt ballistic missile/WMD coercion of NATO, thereby allowing the Alliance to more effectively deter aggression and carry out its military and security obligations.

NATO has been examining the requirements for missile defense for several years. Its past focus has been on the protection of military forces operating outside of Europe against short-range missile threats. The United States, Germany, and the Netherlands, for example, are deploying new shorter-range missile defenses composed of the PAC3 system. Italy, Germany, and the United States are jointly developing the Medium Extended Air Defense System (MEADS) to provide mobile defense for expeditionary forces against short-range missile threats. As ballistic missile threats have evolved in terms of range, technical sophistication, and payload, allies have started to examine 
longer-range missile defenses. Toward this end, in 2001 NATO initiated a major technical feasibility study to define an architecture for protecting Alliance deployed forces operating outside of NATO territory against ballistic missile threats of up to 3,000 km. Known as the Active Layered Theater Ballistic Missile Defense (ALTBMD) program, this effort was completed in 2003. The following year, the supporting technical blueprint and required funding were approved by NATO defense ministers to begin building a command and control "operational backbone" to which nations could contribute missile defense interceptors and sensors in the future.

As important as this work was, it remained limited in scope because it did not examine options for protecting Alliance territory and population centers from longerrange threats. In recognition of the growing risk from missiles, the November 2002 Prague Summit Declaration by NATO heads of state and government stated, "Today we initiated a new NATO Missile Defense Feasibility Study to examine options for protecting Alliance territory, forces, and population centers against the full range of missile threats, which we will continue to assess." This follow-on feasibility study of the architectural options to defend NATO forces, populations, and territory from ballistic missiles of all ranges was completed in July 2005. At the November 2006 Riga Summit, NATO heads of state and government acknowledged the study's findings that missile defense for Alliance territory and populations is technically feasible.

In parallel with these efforts at NATO, the United States carried out a series of detailed technical and architectural assessments examining options to provide protection for Europe and the United States from longer-range ballistic missiles launched from the Middle East. The analysis concluded that the optimal location for defending Europe against limited intermediate- and long-range missile strikes, and for providing additional capability to the current missile defense system located in Alaska and California to defend the United States, is Central Europe. After consultations with interested NATO allies, the United States began formal discussions in January 2007 on basing defenses in Europe.

The current U.S. proposal calls for an interceptor site of up to ten Gibes in Poland similar to those deployed in Alaska and California. The Gibes would be housed in underground silos in an area about the size of a soccer field. These interceptors, like those based in the United States, employ small non-explosive hit-to-kill vehicles to destroy incoming warheads. The interceptors would be supported by a fixed X-band radar in the Czech Republic. They would track and discriminate ballistic missiles in the midcourse portion of their flight. The radar's location would be optimized to point its narrow beam toward the Middle East to detect missiles in flight from that region. The data collected would be used to guide the Gibes to the projected trajectory of the missile warhead. These new missile defense assets would be integrated with existing radars in Fylingdales in the United Kingdom and Thule in Greenland, as well as with the missile defense interceptors located in California and Alaska. Construction of the missile defense sites could begin as early as 2009 , with the first interceptors in place in 2011-12.

The proposed plan offers a way that the United States and its NATO allies can not only cooperate on missile defense, but also maintain the collective security of the Alli- 
ance by creating a defense that would protect all NATO countries facing a long-range ballistic missile threat from the Middle East. Some Alliance members in south eastern Europe would not face these long-range threats given their proximity to the region. Rather, they are more likely to be threatened by shorter-range ballistic missiles. For these countries, short- and medium-range missile defense systems would provide the desired protection. To this end, individual NATO nations are already pursuing shorterrange missile defense systems, and the Alliance, as described above, is developing the ALTBMD program to link them into an integrated command and control network.
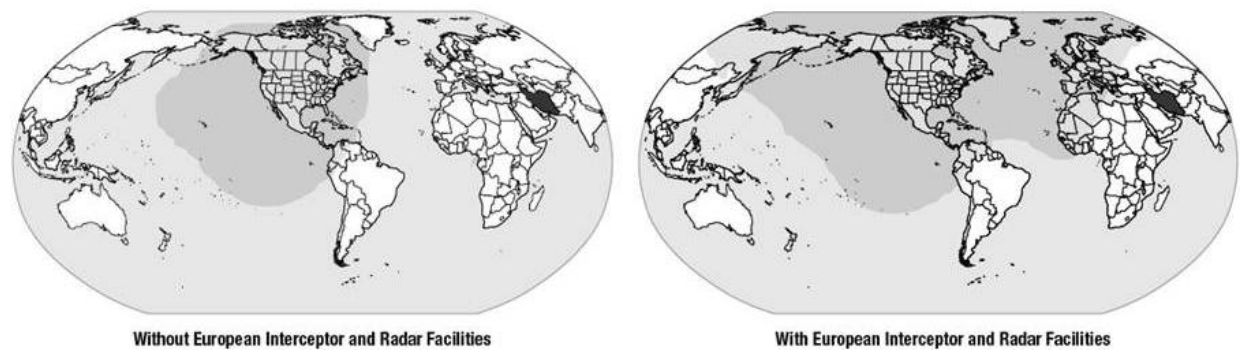

Figure 3: Areas Protected by U.S. Ballistic Missile Defense System.

At the April 2008 NATO summit, heads of government took a major step in moving the Alliance toward a policy on continental defense. They cited a growing threat to Alliance territory and populations arising from proliferation and the "substantial contribution to the protection of allies from long-range ballistic missiles to be provided by the planned deployment of European-based United States missile defense assets" in Central Europe. NATO leaders also stated the importance of exploring ways to link the U.S. long-range missile defense capability with current NATO short-range missile defense efforts through the development of options that NATO would consider at its 2009 summit.

In the framework NATO agreed to, the long-range missile defense assets proposed by the United States could provide a capability to the Alliance that would complement existing and planned NATO missile defense efforts. A long-range defense system in Europe would be interoperable with current Alliance short-range defenses as well as NATO's ALTBMD program. The command and control architecture for the U.S. longrange missile defense system is being designed to be compatible with ALTBMD and the NATO Air Command and Control System, which, when operational, will serve as a unified air command and control network enabling NATO members to seamlessly manage air operations and air defense over Alliance territory. Information on missile defense operations, including data from the U.S. ballistic missile defense system, would be a part of this shared situational awareness. As missile defense systems, operators, and commanders from NATO nations are able to effectively coordinate efforts, 
they should be better positioned to deploy assets efficiently, ensure vital areas are defended, and avoid redundant resource expenditures.

Cooperation on missile defense along this path could lead to significant efficiencies and cost savings, with the United States focusing on long-range defense while NATO systems address shorter-range threats to allies in south eastern Europe. This approach combines Allied national missile defense contributions with possible NATO assets similar to the way the Alliance has fielded capabilities in the past. Such an arrangement would also provide another avenue for burden sharing in Europe, with hosting nations providing a significant contribution to the collective defense of the Alliance. U.S. and European combined efforts in short- and long-range defense would keep U.S. and NATO security indivisible by providing all members with a defense against the full range of ballistic missile threats. With the protection provided by U.S. and allied capabilities in Europe, NATO member states would have an answer should a future hostile state attempt to use WMD-armed ballistic missiles to intimidate or coerce the Alliance regarding actions in defense of its interests.

\section{Consultations with Russia}

Since the January 2007 announcement of U.S. plans to field defenses in Europe to counter limited attacks from potentially hostile states such as Iran, Russia has expressed strong objections. Officials claim the system could nullify Moscow's strategic nuclear arsenal. The United States has been transparent with Russia regarding its plans and capabilities for the long-range missile defense system in Europe, and has encouraged the Kremlin's cooperation against common dangers arising from missiles and WMD in the Middle East and elsewhere. Senior U.S. officials have conducted frequent consultations with their Russian counterparts, as well as Russian experts, on the proposed U.S. defense system.

U.S. officials have explained in detail that the proposed missile defense system for Europe would pose no threat to Moscow's ICBM assets that might be launched from Russia at the United States. Nor would it have any capability against the Russian seabased strategic force of submarine-launched ballistic missiles. Given their proposed location, U.S. long-range interceptors based in Europe could not catch up to Russian missiles in flight - the defensive interceptors would be in a "tail chase." Although a moot point because of the preceding fact, it is evident that ten interceptors would not be able to threaten Russia's strategic force of hundreds of missiles and thousands of warheads. Nor can these systems be used as offensive ballistic missiles or converted to carry warheads. To do so would require significant modifications and testing, all of which would be impossible to undertake clandestinely.

To address Russian concerns, the United States has offered an array of measures to increase transparency in its missile defense activities, including those proposed for Europe. These range from visits to missile defense sites and opportunities to observe related tests to the sharing of information on U.S. missile defense plans and programs. The United States has also been willing to explore cooperation with Russia across the full spectrum of missile defense activities. In 2007, it provided Russia with a compre- 
hensive list of possible cooperative missile defense measures. For example, the United States proposed to develop a joint regional missile defense architecture that could incorporate both U.S. and Russian missile defense assets. This concept could involve any number of linked missile defense assets or systems, all working toward the goal of defending the United States, Europe, and Russia from the shared threat of ballistic missile attack. To date, Moscow has not directly engaged on these cooperative proposals. Instead, it insists that Washington and its allies must suspend plans to deploy long-range missile defenses in Europe. In exchange, Russia has stated that it would be willing to jointly monitor Iranian missile activity and share any relevant data from its early warning radar systems. Despite these differences, the United States is continuing to explore opportunities for cooperation with Russia, both bilaterally and within NATO.

The long lead time involved in building and deploying missile defenses, combined with the growing dangers of nuclear and missile threats, suggests the need for the United States and its NATO allies to address, in a timely and comprehensive manner, how best to move forward with the proposals before them. As they do, several areas merit further attention. The Alliance should:

- Sharpen its focus on the strategic implications of a shift to defending its populations and territory against ballistic missile attacks

- Broaden its understanding of the ways in which missile defense can complement other measures to combat and roll back WMD and missile proliferation

- Expand intelligence-sharing on the extent and timing of WMD and ballistic missile threats to European allies so they may better assess the implications of such threats for stability and the protection of European interests

- Develop a roadmap for the incremental fielding of defenses that integrates shorter- and longer-range systems from those nations with the capacity to make contributions; this should include identifying arrangements for the command and control of such defenses in a way that optimizes the effectiveness of the system and is transparent to all allies.

Together, these efforts would lead to a better understanding of the contribution missile defense can make to strengthening the Atlantic Alliance as it adapts to the security environment of the twenty-first century. 